\title{
Recognition of forest and shrub communities on the base of remotely sensed data supported by ground studies
}

\author{
A Y Denisova ${ }^{1}$, L M Kavelenova ${ }^{1}$, E S Korchikov ${ }^{1}$, A V Pomogaybin ${ }^{1}$, \\ N V Prokhorova ${ }^{1}$, D A Terentyeva ${ }^{1}$, V A Fedoseev ${ }^{1,2}$ and N V Yankov ${ }^{1}$ \\ ${ }^{1}$ Samara National Research University, Moskovskoe Shosse 34A, Samara, Russia, 443086 \\ ${ }^{2}$ Image Processing Systems Institute of RAS - Branch of the FSRC "Crystallography and \\ Photonics" RAS, Molodogvardejskaya street 151, Samara, Russia, 443001 \\ e-mail: denisova_ay@geosamara.ru
}

\begin{abstract}
The forest and shrub communities are important components of the environment and provide a wide spectrum of ecological services. In the Samara region the forest and shrub cover is dispersed on the territory what makes its monitoring difficult. The forest areas are limited by natural and anthropogenic reasons since Samara region is a forest-steppe territory with a high level of human activity. The shrub communities are mostly the secondary ecosystems incorporated in natural grassy communities, agricultural fields or enclosing to forests. These specific ecosystems can be recognized on remote sensing data including satellite images supported by preliminary ground surveys. In this article, we present the study of the forest and shrub communities recognition using remote sensing images and ground surveys in the Samara region. We describe a process of the test site selection for remote sensing data verification and discuss the results of applying the author's classification technology for multispectral remote sensing composites to classify forest communities in the Samara region.
\end{abstract}

\section{Introduction}

Forest ecosystems are effectively involved in biosphere stabilization, planetary biodiversity conservation, environmental management provision being a valuable part of the natural wealth of the Russian Federation. In Russia, forest conservation is better organized than in other countries of the world. However, the forests of the Russian Federation European part show clear negative changes associated with deterioration of their qualitative composition, age and species structure as well as the forest formation changes and the biodiversity reduction [1]. This fact provides the hopefulness of forest communities monitoring using remote sensing (RS) imagery aiming to obtain operational and independent observations of the current territory state.

In Russian Federation forest monitoring results are used at different management levels. At the state level, forest monitoring tasks include "... operational monitoring of changes in the forest fund conditions caused by the forest use, natural and man-made impacts on forests, processing and analysis of these data, making forecasts for the forest protection and conservation, the forest resources rational use and the sustainable development of the forest sector of the Russian economy". The legal basis for forest monitoring is the Establishment of the Council of Ministers of the Russian Federation dated November 24, 1994 N 1229 entitled "On the creation of a unified state system of environmental 
monitoring" and the decision of the Interdepartmental Commission on Environmental Safety of the Security Council of the Russian Federation dated June 16, 1994 N 8, which recognized the need of forest monitoring system development and implementation a as part of a unified state system of environmental monitoring [2]. At the regional level, the functions of forest monitoring include the development and adaptation of methodology and software for organizing and conducting forest monitoring taking into account the specific features of the region [3]. In the Samara region, the forest monitoring tasks can be formulated as the regional verification of the RS data and the development of the forest communities classification technology according to the regional Forest Plan.

This article describes an approach to solve these problems. The approach was developed by the experts in ecology and geoinformatics of Samara University. The approach takes into account the plant communities peculiarities of the Samara region. The article presents the results of the global statistics analysis made using the open information sources about the nature of forest and shrub communities changes in the region. The article describes the steps of the ground control polygons selection for the regional verification of remote sensing data. The article considers the authors' technology of the supervised spatial classification based on seasonal composites of multispectral remote sensing data to define tree species for the test sites. The experimental results of classification technology testing for a territory with a known Forest Plan are also provided. Finally, the article includes some results on the analysis of the Forest Plan classification using verified remote sensing data in order to identify plant community changes.

\section{Forest and shrub communities characteristics in Samara region}

The tree species dominance in mature forests is determined by geographic latitude changes. There are three main forest regions in Russia such as boreal, hemiboreal and nemoral. The north-eastern part of the Samara region belongs to nemoral forest region. For a nemoral region, the deciduous forests and the forest-steppe landscapes are the most typical [4,5].

According to the climatic conditions, the Samara region is a territory where the transition from forest-steppe to steppe takes place [6]. Since 1996 all the region forests were transferred to the first ecological group corresponding to the ecological situation [7]. In accordance with the forest vegetation zones approved by the order of the Ministry of Agriculture of Russia dated March 9, 2011 No. 61, the forests of the Samara region are assigned to the forest-steppe zone of the forest-steppe region of the European part of Russian Federation. All forests in the region belong to the protected areas in order to preserve the different types of natural resources. The forests play an important sanitary, hygienic, health and other useful roles [8] in the region.

Due to the peculiarities of the regional natural conditions as well as the high anthropogenic transformation of the region, the areas covered with forest are highly fragmented. The whole forest coverage of the Samara region is about $12.8 \%$ of the total region area. The forest coverage for the different municipal subregions varies from $2 \%$ or less in the southern areas to $22-25 \%$ in the northern and northwestern areas $[8,9]$.

From the beginning of the 19th century, the general forests change trends in the Samara region reflect a significant forest transformation. Forest area reduced in more than two times. A clear species composition changes including oak participation decreased and the aspen forests area increased as well as the tree age structure changes were detected. For example, the relict upland forest area and oak forest area continue to decrease in Zhiguli [10].

Figure 1 demonstrates the official statistical data characterizing the general indicators of the forests in the Samara region in recent years. The statistical data reflect a slight decrease and a subsequent return of the forest area indicators to the 2004 level. The more important point of the qualitative forest changes is the reduction in the young and middle-aged forests fraction as well as the increase in the fraction of ripe and over-mature forests.

Figure 1 demonstrates that the species composition changes show the tendencies of the aspen and oak-occupied areas decrease and the simultaneous increase in the fraction of maple, ash, elm, poplar and shrubs-occupied areas. 

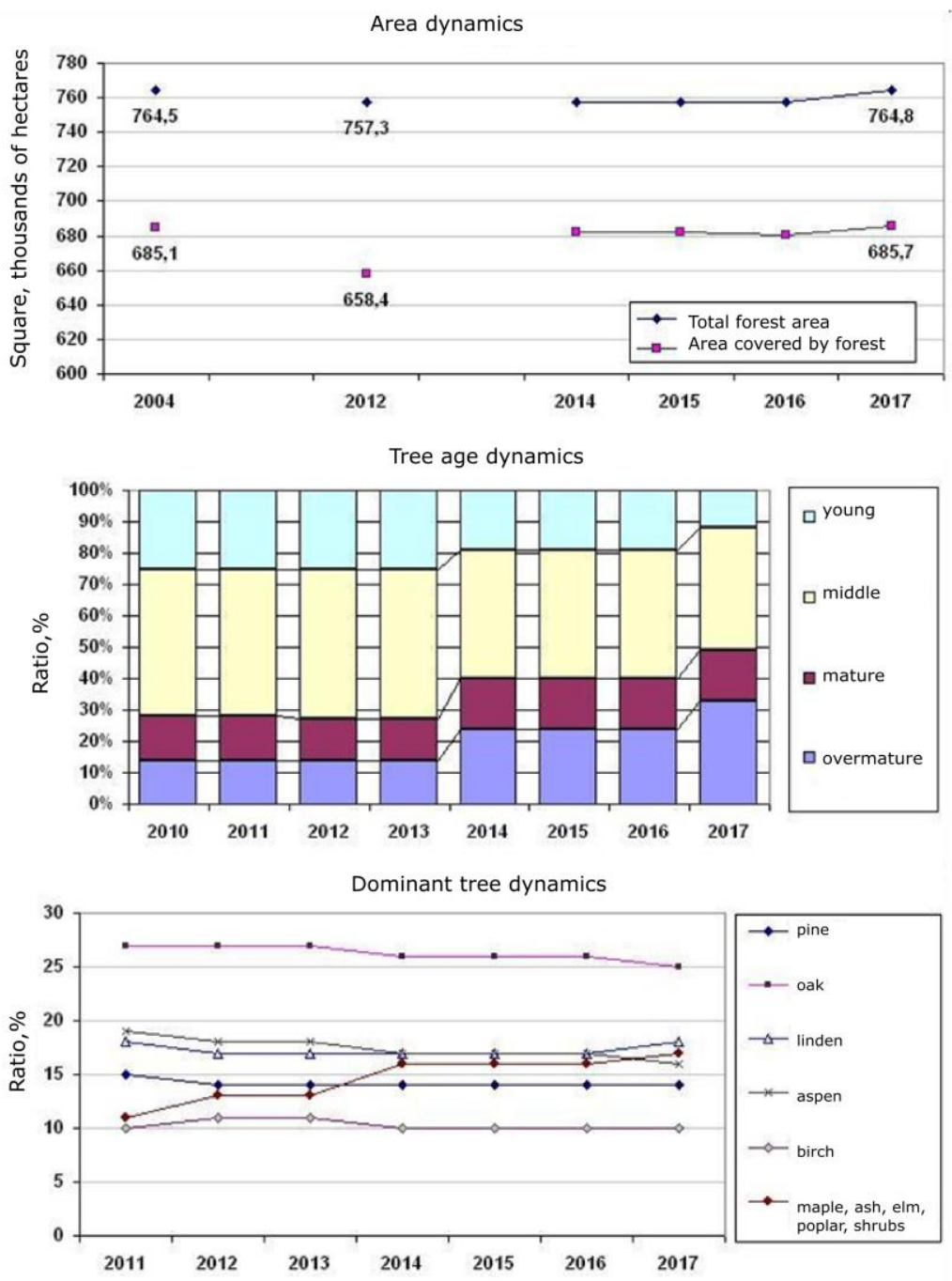

Figure 1. Overall dynamics of forests indicators in the Samara region in recent years (compiled according to the State reports from 2004 to 2017 [6,9-16]).

Thus, the peculiarities of the forest plant communities in the Samara region are:

1. The originality of the vegetation cover in terms of its ecosystem diversity, orographic localization, geology and soil characteristics;

2. The presence of natural forests in the regional forest fund as well as the anthropogenic forests of various types and the secondary forest ecosystems developing during the revitalization of the disturbed areas and fallow lands;

3. The significant heterogeneity of tree plantations in terms of area, localization, species and age composition, increasing due to succession changes;

4. The considerable fragmentation and different affiliation of regional forest fund components.

These peculiarities approve the necessity of a ground reference polygons network with a detailed description in order to classify the regional forest and shrub communities. The reference polygons network will be subsequently used for verification of the methods and algorithms applied to remote sensing data obtained for the territory of the Samara region.

\section{Test site selection for remote sensing data verification}

To verify the results of manual decryption of remote sensing images and their automatic classification, the reference data must be available. For this reason, the regional network of the ground control polygons is needed to ensure the possibility of the remote sensing data verification and to set up the algorithms and technologies for the remote sensing data analysis taking into account the regional 
specifics, i.e. the features of the territory composition and climatic features in the region. Since 2017, the specialists from Samara University have been working on the creation of the ground reference polygons network in the Samara Region. The target vegetation types include plant communities valuable for the regional biological diversity conservation.

In 2018, a group of ecologists from this article authors' team carried out a survey of the new ground control polygons belonging to the category of forest and shrub communities. The ground control polygons are located in the Krasnosamarsky and Novosemeikinsky forests of Samara region. A ground survey was carried out on the homogeneous species composition for these sites that can serve as a refugiums of protected species. For example, the oak and birch forests are the areas where the rare species of orchids and ferns grow.

Three ground control polygons were selected. They are shown in Figure 2. Polygon No. 1 is covered by birch, Polygons No. 2-3 correspond to the oak forests. Polygon No. 2 contains also insignificant birch impurities with the concentration less than 1\%. Polygon No. 3 is characterized by the presence of birch and aspen impurities with the impurity concentration up to $10 \%$. Due to the weather conditions in 2018 such as a long and cold spring with a rapid vegetation onset upon the hot weather beginning, the summer field surveys did not capture the phenological moment of the most distinguishable deciduous tree species and this fact was limited the number of surveys in this direction.
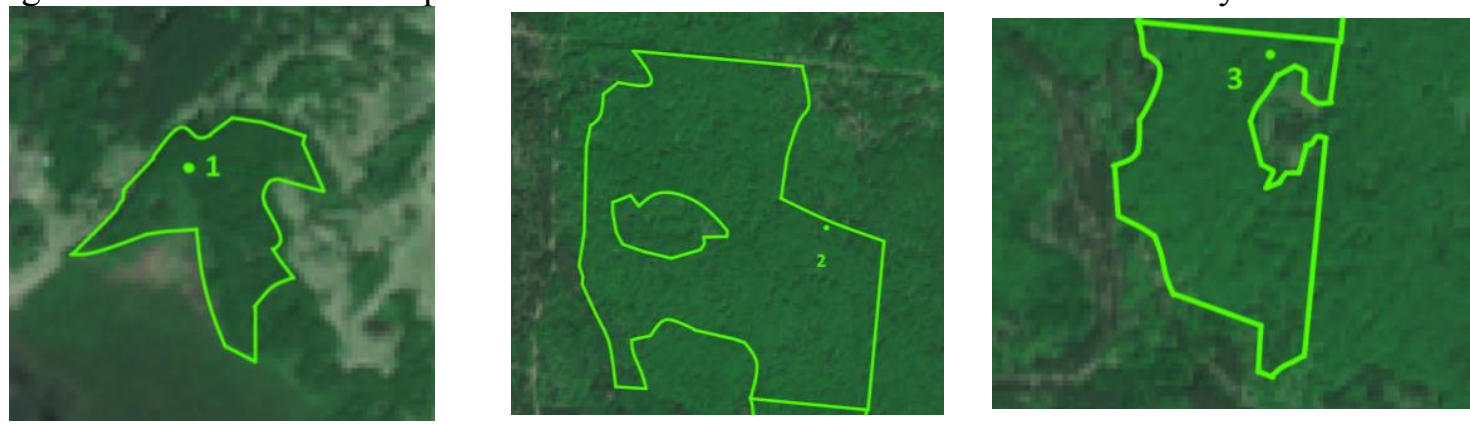

Figure 2. Ground control polygons for birch and oak forests (initial ground survey).

The survey of the shrub communities was carried out in the same period and allowed us to identify six polygons in the Bolshechernigovsky and Kinelsky districts of the Samara region. The centers of the selected polygons are shown in Figure 3.
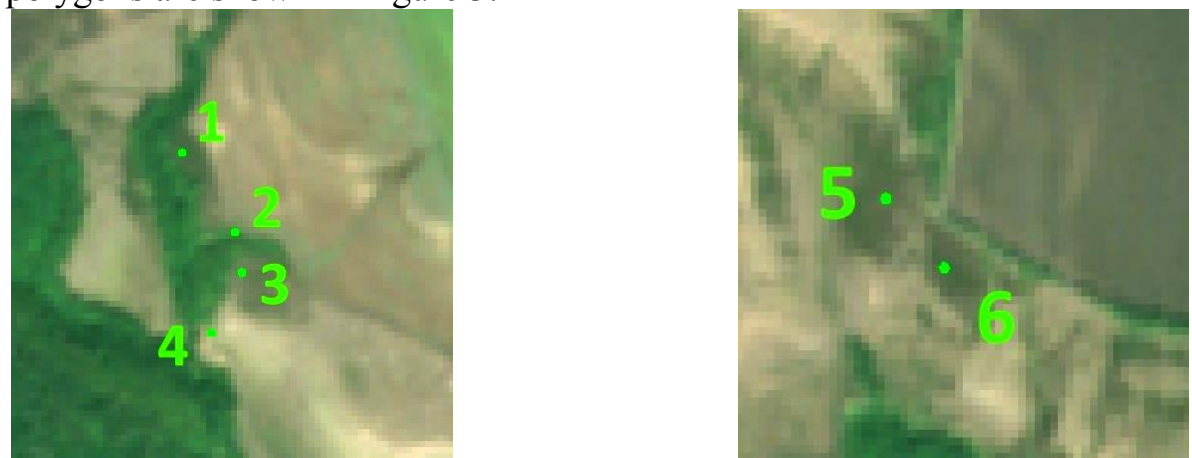

Figure 3. The centers of the ground reference polygons of shrub communities.

In Figure3, Polygon No. 1 and No. 2 represent an unbroken shrub steppe with a projective cover of shrub crowns about $50 \%$. The Polygon No. 1 is characterized by the predominance of Cytisus ruthenicus and Caragana frutex, for the Polygon No. 2 is dominated by Caragana frutex and Amygdalus nana. Polygon No. 3 is a closed shrub steppe with the projective cover of shrub crowns equal to $100 \%$ with a predominance of Caragana frutex. Polygon No.4 is the slope with feather grass steppe and does not contain shrubs. Polygon No. 5 is characterized by uneven overgrowing with shrubs with the average projective cover about $80-90 \%$. Polygon No. 5 is characterized by shrubs of Caragana frutex as a monodominant and by an admixture of individual Ulmus foliaceae trees. Polygon No. 6 corresponds to a shrub steppe with the high crowns closeness and projective cover of shrubs 
over $80 \%$. The shrubs presented in Polygon No. 6 are $80 \%$ of Caragana frutex and $20 \%$ of Amygdalus nana. All selected shrub communities were presented by small areas of the size $100 \times 100 \mathrm{~m}$ and less. Most of the shrub communities were located on the slopes with a noticeable height difference from 3 to $20 \mathrm{~m}$ and arranged along the borders of more massive forest and steppe communities.

A survey of shrub communities has shown that due to their secondary nature it is difficult to select fairly large homogeneous areas for them, Figure 4.
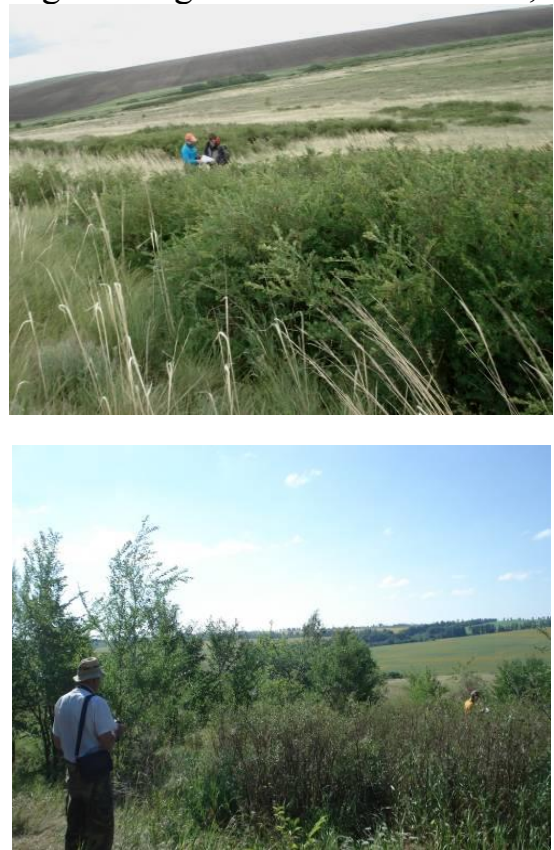
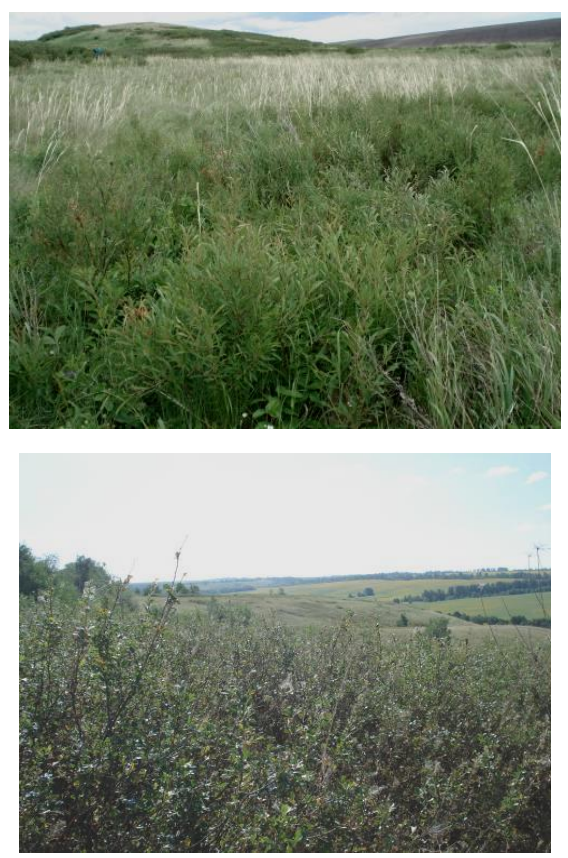

Figure 4. General view of the shrub communities, June-July 2018 (upper photos Bolshechernigovsky, lower photos - Kinelsky district of the Samara region).

In addition, the field surveys have confirmed that shrub communities are poor by rare species of higher plants. However, shrub communities deserve further study because, due to agricultural landscapes environment around, they actually become the shelters for the fauna representatives including protected species of mammalian, birds and insects.

It is obvious that the volume of allocated ground control polygons does not allow confident recognition of the forest and shrub communities due to the small size and the insufficient number of the test sites. However, the information about these polygons can be used to refine the classification results that were obtained by the training based on the geo-information data sources, for example, the maps of the protected natural territories and Forest plan. These data sources cannot be used without clarification due to the long period of update of geo-information data sources and paper cartographic materials. Thus, the clarification using ground control polygons will lead to an increase in the classification accuracy by means of the classification results verification.

\section{Supervised local classification technology for detailed forest classification using multi- temporal remote sensing data}

In this section, we describe a forest classification technology developed earlier by the part of the authors' team and deliver the results of its application to the forest classification. We selected forest communities as the object of our experimental research because there are available regional Forest Plan data of the 2013-2014 years. The regional Forest Plan gives detailed information on tree species fraction for each forest parcel and can be used to train the classifier. As for the shrub communities, there were not enough amount of detailed ground truth data and the selected ground control polygons were too small to get the proper classification accuracy. Moreover, the small size of the shrub communities requires high-resolution images to be used for classification. But there were no available 
high-resolution images at the moment of the research for the test site. Thus, we left the shrub classification for future research.

The classification technology applied in this paper uses the multi-temporal remote sensing image composites as input. From the point of view of the plant-community analysis, the composites of multitemporal multispectral images obtained during the vegetation season provide a more comprehensive vegetation description because they reflect the differences in vegetation phenology. The classification is based on the spatial processing methods and the pixel-wise classification methods investigated in [17-18]. Originally, the technology was tested for the vegetation classification using hyperspectral data. This fact confirms its applicability to the multidimensional datasets.

\subsection{Classification technology}

The classifier applies a composite of medium-resolution multispectral images, a training sample mask at the training stage and a test sample mask at the classification stage as input data. The image composite includes all spectral channels of all available cloudless images obtained during the vegetation season. The spectral bands necessarily include the channels related to the near-infrared (NIR) and red (R) spectral ranges characterizing the presence and density of green vegetation. The training sample mask represents an image of class labels defined for the image parts with the known classification. The test sample mask marks the pixels to be classified by the value "1" and "0", otherwise. The classifier output is an image containing the class labels for each pixel.

The overall classification technology involves the following stages:

1. Feature extraction.

2. Spatial preprocessing.

3. Clustering.

4. Segmentation.

5. Supervised pixel-wise classification.

6. Merging classification and segmentation results.

7. Spatial post-processing.

The feature extraction is performed by the dimension reduction using principal component analysis (PCA) method [19] and data normalization. The latter is used to place the features into the range $[-1,1]$ that simplifies the further pixel-wise classification.

Spatial preprocessing aims to reduce the level of noise in data keeping the edges in image as most as possible. We carry out spatial preprocessing using the median filter of the small size $N \times N$.

Clustering is used to find the groups of pixels with a similar feature description regardless of their spatial arrangement. In this paper, we applied the generalized expectation-maximization (GEM) clustering algorithm to implement this step [20]. GEM algorithm estimates the cluster count and cluster parameters according to the Gaussian mixture model of the data distribution. The algorithm assigns cluster labels according to the maximum conditional probability rule.

During the segmentation stage, a spatial connectivity analysis of the clustering results is provided to obtain the segments that are homogenous in both spatial and feature domains. It is likely that each particular image segment entirely corresponds to one vegetation class. Both stages segmentation and clustering may be implemented as a single segmentation process adapted to the seasonal data processing, for example, using the method [21].

To implement the supervised pixel-wise classification we selected the support vector machine classification with the radial basis functions (SVM-RBF)[22]. This algorithm is one of the best pixelwise classifiers tested with the hyperspectral images of vegetation [23]. The algorithm is trained using the training sample mask and the training feature image. The classification model obtained after training is used for the further test sample classification.

At the next stage, we perform merging of the pixel-wise classification and segmentation results. For this purpose, the majority voting is used by the segments, i.e. the final class label is the same for all pixels belonging to the same segment and it is defined as the most frequent class label for this segment. The resulting image is spatially much more homogenous than the image after pixel-wise classification. 
Finally, spatial post-processing is performed. This kind of spatial post-processing was proposed in [18]. It is organized as the sliding window filter of size $M \times M$ and threshold $T$. For each window position, the dominant class is defined. If the number of pixels belonging to the window and corresponding to the dominant class exceeds the threshold $T$ and the class label of the current pixel differs from the dominant class label, the current pixel class is substituted by the dominant class label. This spatial post-processing algorithm is an analogue of the median filtration and tends to minimize the amount of singular misclassified pixels.

\subsection{Forest classification using the proposed technology}

To train our classifier we applied the available Forest plan data as the ground truth information. These data represent a vector map of the forest parcels with the detailed tree species description. However, the last available Forest plan was made during the 2013-2014 years. Since the situation is likely to be changed for the past 5 years, the training sample obtained from the Forest plan might contain errors and lead to the classification inaccuracies as a result.

To estimate the classification accuracy more precisely we performed our study in the following way. We divided the available Forest plan data into the training and control sets. Both sets included the forest parcels occupied mostly with one type of tree species and the dominant tree species fraction was more than $80 \%$. Then, we trained the classifier using the training set and applied it to the control set to estimate the basic achievable classification accuracy. After that, we extracted the largest parcels that were classified differently from the Forest plan data. Extracted parcels were used for the ground survey to discover the reasons for misclassification. Finally, we corrected training and control sets using the ground truth data obtained by the survey and estimated the classification accuracy using the corrected ones.

The experimental research was conducted for the Krasnosamarskoye forestry as a test site. It is the largest forest area in the Samara region. The remote sensing data included 17 cloud-free and atmospherically corrected Sentinel-2 [24] images obtained for the period from April to October 2018. The multi-temporal image composite derived from these images contained 136 components in 8 spectral bands. The spatial resolution of the image composite was 10 meters. We omitted the spectral channels with the original spatial resolution of 60 meters and applied an image sharpening to convert 20-meters channels into 10-meters representation using Scanex Image Processor software [25].

The forest parcels extracted from the Forest plan data included 9 tree classes: birch, elm, oak, willow, maple, aspen, pine, poplar and ash. The vector objects of forest parcels were converted into compatible raster representation i.e. the mask image with the class labels had the same spatial resolution as the remote sensing image composite.

The training and control mask images were generated separately and composed two different pixel sets with empty intersection. We formed our training set by the random selection of pixels from the northern part of the forest. To avoid the classifier adaptation to the particular class distribution, we included the fixed number of pixels per each class into the training set. As a result, our training set contained 2000 pixels per each class. The parcels from the southern part of the forest constituted the control set.

To obtain the classification results we applied the classification technology described above with the following parameters. The number of PCA components used as features was 40 and the preprocessing and post-processing spatial filtration parameters were $N=3, M=3, T=5$. The achieved classification accuracy for the control set was 0.8160 . Figure 5 demonstrates the largest 43 misclassified forest parcels. For these parcels, the classification results mismatched the original Forest plan data.

\subsection{Classification error analysis}

The forest parcels defined as the ground polygons for remote sensing data verification confirmed the correct classification of these parcels using the proposed classification methodology. A large area of these parcels explaines the long-term resistance of their vegetation communities to significant changes. This fact allows us to conclude that the selected ground polygons are suitable for verification 
of remote sensing data in a wide time interval if the changes caused by emergency and anthropogenic activities remain minimal for these polygons.
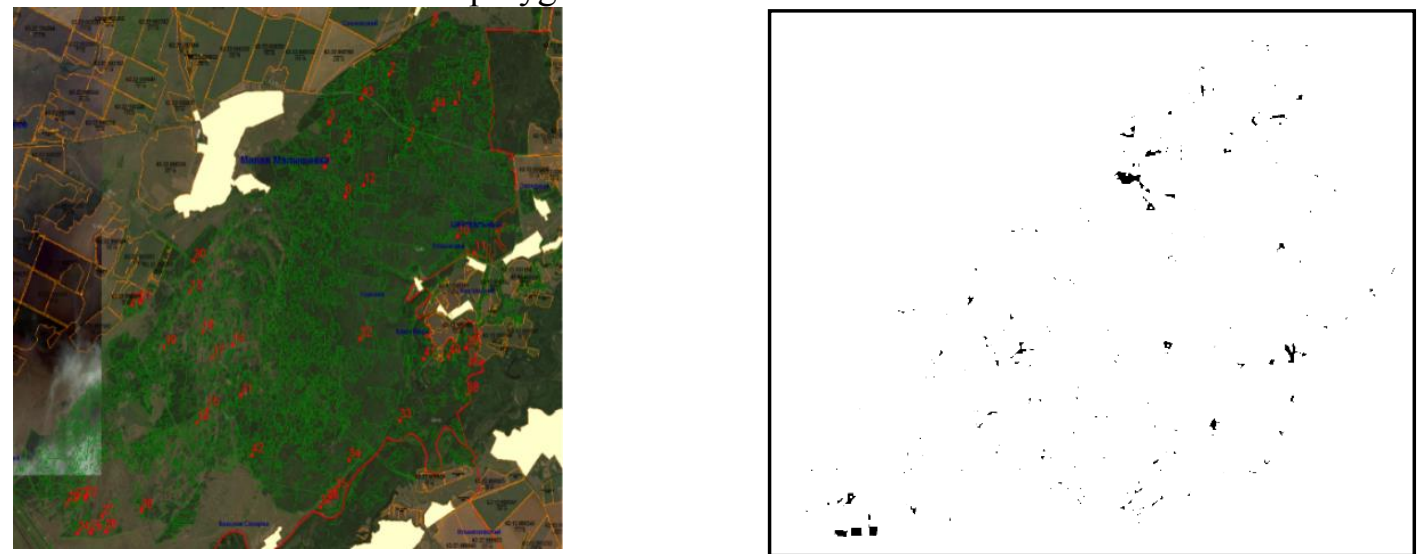

Figure 5. 43 largest forest parcels with classification errors: the map (left) and the mask (right).

As for the forest parcels with an erroneous classification for which the Forest plan data do not coincide with the classification results, we made an additional analysis to identify the causes of the erroneous classification. 13 of the 43 largest forest parcels were selected to be verified by the ground survey that was conducted in the autumn of 2018. The survey included an assessment of the tree species composition and a determination of the current ecosystem status.

The survey demonstrated that 8 from 13 visited parcels have unsatisfactory Forest plan data that do not correspond to the current state of the forest. Figure 6 shows the examples of the changes occurred in the observed forest parcels.
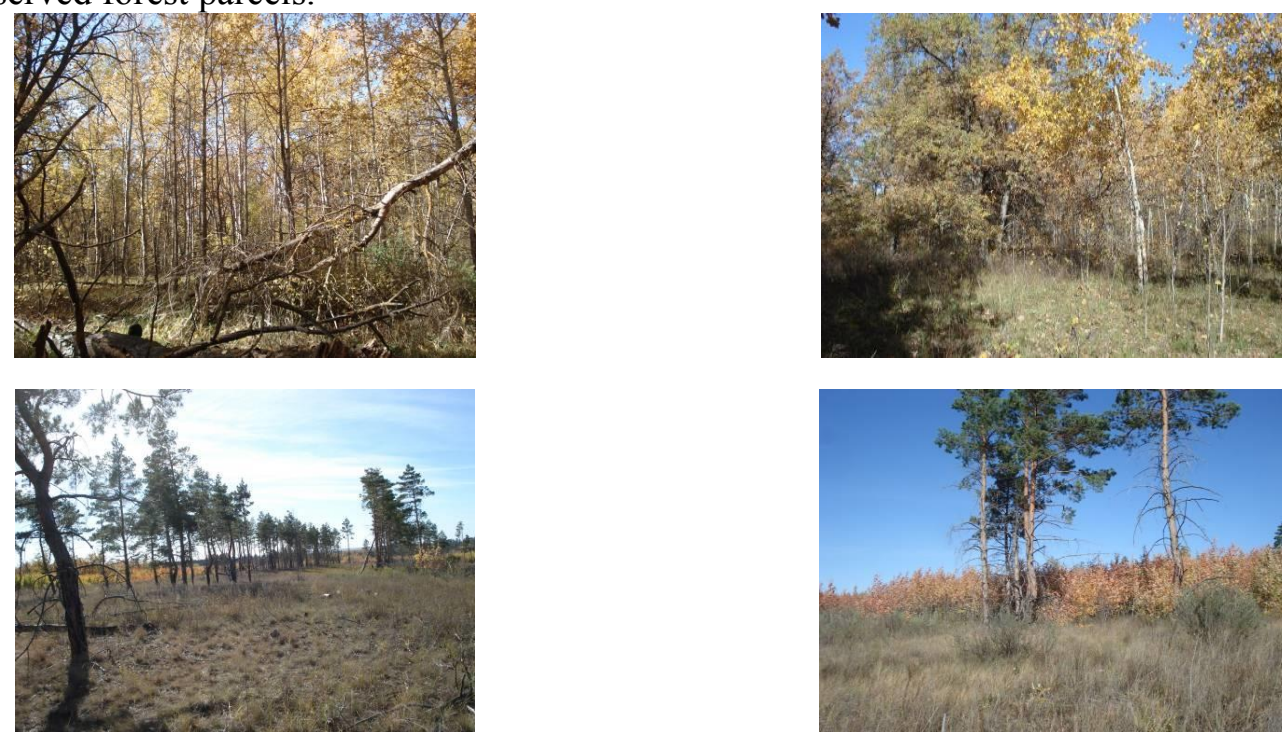

Figure 6. The changes in forest parcels of the Krasnosamarskoye forestry: the loss of old trees and the introduction of young ones (upper images); burned conifer areas (bottom images).

The discovered reasons for the Forest plan data inconsistency are listed below

1. The loss of old trees and the introduction of young ones of other tree species into the emerging places leading to a partial change of the dominant tree species and the spatial distribution pattern of the forest.

2. The burning down of the tree layer as a result of fires in recent years leading to parcel overgrowing by aspen and birch.

3. The young age of conifer in some parcels leading to the different spectral reflection in comparison with the ripe conifer.

4. The inaccuracies in forest parcel partition in the Forest plan used. 


\section{Conclusion}

The research presented in this paper deals with the problem of forest and shrub vegetation communities estimation using remote sensing data in the Samara region. The paper addresses such issues as the ground control polygons selection for the remote sensing data verification, the classification accuracy assessment for the regional forest sites and the reasons for possible misclassification. We conducted our study in three stages including a preliminary ground survey, remote sensing data classification and the classification error analysis supplemented by the final ground survey.

As a result of the preliminary ground survey, a set of ground control polygons corresponding to different forest and shrub communities was selected. These polygons were included in the regional ground control polygons network that can be used for remote sensing data verification in the natural vegetation studies in the Samara region. For the selected polygons, up-to-date description of the vegetation state was described.

During the classification stage, we applied the earlier developed original classification technology. The training and control sets were defined using the available Forest plan data. The classification accuracy achieved was 0.8160 .

The classification results analysis made for the selected ground control polygons of forest vegetation showed that the selected polygons are resistant to significant changes over the past 5 years and, therefore, they represent the sustainable plant communities that can be used to verify other classification methods and algorithms of these communities in the Samara region.

To analyze the discrepancy between the classification results and the Forest Plan, an additional ground survey of the largest sites with discrepancies was made. The survey revealed that the classification errors mostly deal with the inaccuracies in the forest parcel boundary of the Forest plan and with the significant changes in the dominant species composition within these areas. Overall classification error analysis confirmed the effectiveness of the forest classification by the technology regarded in this paper since the classification errors highlight the forest parcels with significant tree species changes.

As for the shrub communities, it was found that in the Samara region these communities are arranged in the small places with the significant elevation difference (from 3 to 20 meters). Therefore, the study of shrub communities requires the use of high-resolution remote sensing instruments or unmanned aerial vehicles to obtain the representative remote sensing dataset. The future research is planned to involve these types of data for the shrub communities investigations.

\section{References}

[1] 2002 National Strategy for the Biodiversity Conservation of Russia (Moscow: Ministry of Natural Resources of the Russian Federation) p 129

[2] 1995 Regulation on forest monitoring. Letter dated 11.29.95, N MG-1-17-6 / 287 (Moscow: Federal Service of Forestry of Russia)

[3] Tarankov V I 2006 Monitoring of forest ecosystems (Voronezh: Publishing house of the Voronezh State Forestry Academy) p 299

[4] Smirnova O V 1994 Eastern European deciduous forests (Moscow: Nauka) p 364

[5] Smirnova O V, Bobrovsky M V and Khanina L G 2017 European Russian Forests (Springer) p 572

[6] 2014 State report on the state of the environment and natural resources of the Samara region for 2013 (Samara) 24 p 283

[7] Polievktova E V 2007 Economic Encyclopedia of Russian Regions. Samara Region (Moscow, CJSC "Economy") p 396

[8] 2018 Report on the environmental situation in the Samara region for 2017 (Samara) 28 p 226

[9] 2017 State Report on the State of the Environment and Natural Resources of the Samara Region for 2016 (Samara) 27 p 198

[10] 2015 State report on the state of the environment and natural resources of the Samara region for 2014 (Samara) 25 p 298

[11] 2005 State Report On the State of the Environment of the Samara Region in 2004 (Samara) 15 p 
214

[12] 2010 State Report on the State of the Environment and Natural Resources of the Samara Region for 2010 (Samara) 21 p 336

[13] 2012 State report on the state of the environment and natural resources of the Samara region for 2011 (Samara) 22 p 343

[14] 2013 The State Report on the State of the Environment and Natural Resources of the Samara Region for 2012 (Samara) 23 p 397

[15] 2016 State Report on the State of the Environment and Natural Resources of the Samara Region for 2015 (Samara) 26 p 296

[16] 2017 State Report on the State of the Environment and Natural Resources of the Samara Region for 2016 (Samara) 27 p 198

[17] Borzov S M and Potaturkin O I 2014 Vegetation cover type classification using hyperspectral remote sensing Vestnik NSU. Series: Information Technologies 12 13-22

[18] Fedoseev V A 2018 Hyperspectral satellite image classification using small training data from its samples Journal of Physics: Conference Series 1096012042

[19] Wold S, Esbensen K and Geladi P 1987 Principal Component Analysis Chemometrics and intelligent laboratory systems 2 37-52

[20] Denisova A Y and Sergeyev V V 2018 EM clustering algorithm modification using multivariate hierarchical histogram in the case of undefined cluster number Proceedings of SPIE $10806108064 \mathrm{H}$

[21] Plotnikov D E, Kolbudaev P A and Bartalev S A 2018 Identification of dynamically homogeneous areas with time series segmentation of remote sensing data Computer Optics 42(3) 447-456 DOI: 10.18287/2412-6179-2018-42-3-447-456

[22] Zhang T 2001 An Introduction to Support Vector Machines and Other Kernel-based Learning Methods AI Magazine 22 103-104

[23] Bibikov S A, Kazanskiy N L and Fursov V A 2018 Vegetation type recognition in hyperspectral images using a conjugacy indicator Computer Optics 42(5) 846-854 DOI: $10.18287 / 2412-6179$ 2018-42-5-846-854

[24] Drusch M, Del Bello U, Carlier S, Colin O, Fernandez V, Gascon F, Hoersch B, Isola C, Laberinti P, Martimort P, Meygret A, Spoto F, Sy O, Marchese F and Bargellini P 2012 Sentinel-2: ESA's optical high-resolution mission for GMES operational services Remote sensing of Environment 120 25-36

[25] 2019 Scanex Image Processor URL: http://www.scanex.ru/upload/iblock/ c16/c16cb3ad6f737ff7dc13271fb4c9e335.pdf

\section{Acknowledgements}

The research was supported by RFBR projects 16-29-09494 ofi_m, 18-07-00748 a, 19-07-00357 a and the Russian Federation Ministry of Science and Higher Education within a state contract with the "Crystallography and Photonics" Research Center of the RAS under agreement 007-ГЗ/Ч3363/26. 